\title{
DETERMINAN YANG BERHUBUNGAN DENGAN KEJADIAN MALARIA DI INDONESIA TAHUN 2016
}

\author{
Determinants Related to Malaria Incidence in Indonesia, 2016
}

\author{
Ummi Kalsum $^{1}$ Diah Restu Pertiwi ${ }^{2}$ Adelina Livia Veronica $^{2}$ Aprina Wulandari $^{2}$ \\ ${ }^{1}$ Dosen Program Studi Kesehatan Masyarakat, Fakultas Kesehatan Masyarakat Universitas Jambi \\ ${ }^{2}$ Program Studi Kesehatan Masyarakat, Fakultas Kesehatan Masyarakat Universitas Jambi
}

\begin{abstract}
Abstrak
Malaria merupakan penyakit infeksi penyebab kematian global. Annual Malaria Incidence (AMI) secara nasional 2,9 \%. Annual Parasite Incidence (API) tahun 2007 hingga 2009 sangat tinggi, masing-masing sebesar $32 \%, 28 \%, 31 \%$, sedangkan rata-rata API Nasional $(<5 \%)$. Banyak faktor yang berkorelasi dengan kejadian Malaria, diantaranya sosial ekonomi dan kesehatan lingkungan. Penelitian ini bertujuan untuk mengidentifikasi determinan yang berhubungan dengan kejadian malaria. Jenis penelitian adalah studi ekologi. Populasi dan unit analisis adalah semua Provinsi yang ada di Indonesia tahun 2016 sebanyak 34 Provinsi, menggunakan sumber data Profil Kesehatan Indonesia dan Laporan Badan Pusat Statistik tahun 2016. Analisis univariate dilakukan terhadap distribusi faktor risiko Malaria dan Analisis bivariate dengan korelasi spearman pada tingkat kepercayaan 95\%, juga dilakukan analisis trend kejadian Malaria (API) selama sepuluh tahun di Indonesia. Hasil penelitian diketahui ada hubungan proporsi penduduk ber-pendidikan rendah $(\mathrm{r}=0,42)$, penduduk miskin $(\mathrm{r}=0,47)$, rumah tangga kumuh $(\mathrm{r}=0,57)$, proporsi desa ber-sanitasi total berbasis masyarakat $(\mathrm{r}=-0,41)$ dan proporsi akses sanitasi layak $(r=-42)$ dengan kejadian Malaria. Tidak ada korelasi antara luas lahan kebun sawit, jumlah perusahaan tambang dan jumlah petani karet dengan kejadian Malaria. Diperlukan upaya-upaya peningkatan ekonomi kerakyatan agar sosial ekonomi masyarakat meningkat serta edukasi tentang sanitasi dan kesehatan lingkungan untuk menekan kejadian malaria.
\end{abstract}

Kata Kunci: Malaria, miskin, STBM, sanitasi, ekologi.

\begin{abstract}
Malaria is an infectious disease that causes global death. National Malaria Incidence (AMI) was $2.9 \%$. Annual Parasite Incidence (API) from 2007 to 2009 was high, 32\%o, 28 \%o, 31 \%o respectively, while the National API average $(<5 \%$ ). Many factors have correlation to Malaria Incidence. This study aims to identify determinants related to Malaria incidence. This research was ecological study. The population and unit of analysis were all Provinces in Indonesia in 2016 (34 provinces). This study used data from the Indonesian Health Profile and the Central Statistics Agency in 2016. Univariate analysis of the distribution of Malaria risk factors and bivariate analysis used spearman correlation tests at a 95\% confidence level. An analysis of the trend of Malaria (API) was carried out for the past ten years in Indonesia. The results of this study revealed that there was a correlation between the proportion of low education levels $(r=0.42)$, poor population $(r=0.47)$, slum households $(r=0.57)$, the proportion of villages based on community sanitation $(\mathrm{r}=0.41)$ and the percentage of access to proper sanitation $(r=0.42$. No correlation of oil palm plantation area, number of mining companies and number of rubber farmers to Malaria indicende. Improving people's economy level are needed so that the socio-economic level of the community could be improved and also need to improve communication and education on sanitation and environmental health, so can reduce the incidence of Malaria.
\end{abstract}

Keywords: Malaria, poor, STBM, sanitation, ecology.

Korespondensi: Ummi Kalsum

Email: ummi2103@unja.ac.id 


\section{PENDAHULUAN}

Malaria adalah suatu penyakit yang disebabkan oleh parasit plasmodium ditularkan melalui gigitan nyamuk anhopeles betina. Malaria merupakan penyakit infeksi penyebab kematian kelima di dunia setelah infeksi pernapasan, HIV/AIDS, diare, dan tuberkulosis. Malaria telah menyerang 106 negara di dunia. Komitmen global pada Sustainable Development Goals (SDGs) menjamin kehidupan yang sehat dan mengupayakan kesejahteraan bagi semua orang, salah satunya yaitu dengan mengakhiri epidemi malaria. ${ }^{1}$ (Info Datin, 2016)

Pada tahun 2006 dilaporkan, dari 109 negara didunia terdapat 3,3 miliar penduduk berisiko malaria dan 247 juta diantaranya menderita malaria, diketahui satu juta orang meninggal setiap tahunnya. Dari 109 negara tersebut, 45 negara diantaranya terdapat di kawasan Afrika yang merupakan kawasan tingkat endemitas tinggi. ${ }^{2}$ Pada tahun 2012 terdapat 627.000 kasus malaria yang meninggal dari 207 juta jumlah kasus Malaria didunia. ${ }^{3}$

Di Indonesia pada tahun 2015 terdapat 255.602.872 penduduk berisiko malaria, diketahui 217.025 diantaranya positif Malaria. Provinsi di wilayah timur Indonesia masih memiliki angka API tertinggi. ${ }^{4}$ Annual Malaria Incidence (AMI) secara nasional 2,9 \% dan provinsi dengan AMI tertinggi yaitu Papua Barat (26,1\%). Annual Parasite Incidence (API) pada tahun 2007 hingga tahun 2009 sangat tinggi, dengan masing-masing sebesar $32 \%, 28 \%$,31\%o, sedangkan rata-rata API Nasional $(<5 \%)^{5}$

Salah satu faktor yang berhubungan dengan kejadian malaria adalah lingkungan dimana lingkungan sekitar rumah sangat mempengaruhi tempat perkembangbiakan penyakit malaria melalui nyamuk Anopheles. ${ }^{6}$ Pembangunan sanitasi di Indonesia menjadi masalah yang relatif kompleks. Masih banyak pemerintah kabupaten yang belum mampu mengurus dan memecahkan masalah di bidang sanitasi dan hygiene. Masyarakat miskin di wilayah perdesaan dan perkotaan memiliki akses yang rendah terhadap pemanfaatan sanitasi. $^{7}$

Hasil studi literature bahwa faktor risiko yang diduga berperanan terhadap kejadian malaria diantaranya adalah tingkat pendidikan masyarakat yang rendah, tingkat kemiskinan penduduk, wilayah/permukiman kumuh, kepadatan penduduk, tingkat sanitasi lingkungan, luas lahan perkebunan, banyaknya perusahaan tambang, dan jumlah petani karet. Derajat kesehatan masyarakat yang masih rendah dipengaruhi oleh berbagai faktor antara lain kemampuan ekonomi yang lemah, dan rendahnya pendidikan sehingga menimbulkan kurangnya pengetahuan masyarakat. ${ }^{8}$

Penelitian yang dilakukan di Kabupaten Sarolangun Provinsi Jambi menunjukkan masyarakat dengan tingkat pendidikan rendah berpeluang terkena malaria 1,8 kali lebih besar dibandingkan dengan tingkat pendidikan tinggi, dan hasil studi yang dilakukan di Fakfak menunjukkan kondisi fisik rumah yang kurang baik diantaranya keadaan dinding, ventilasi, jendela, atap rumah, berisiko 4,4 kali lebih besar dibanding kondisi rumah yang tergolong baik. ${ }^{9}$

Penelitian ini bertujuan untuk mengidentifikasi determinan yang berkorelasi dengan kejadian malaria di Indonesia tahun 2016.

\section{METODE}

Jenis penelitian yang digunakan adalah studi ekologi. Studi ekologi merupakan suatu desain penelitian yang berfokus mengamati kelompok populasi (aggregate), bukan penelitian terhadap individu. ${ }^{10}$

Penelitian ini menggunakan data Profil Kesehatan Indonesia dan Badan Pusat Statistik tahun 2016. Populasi dan unit analisis adalah seluruh Provinsi yang ada di Indonesia pada 
tahun 2016 sebanyak 34 Provinsi. Variabel independen adalah persentase masyarakat berpendidikan rendah dengan nilai melebihi 100 persen yang menunjukkan masih adanya penduduk yang terlalu cepat sekolah (penduduk usia dibawah 7 tahun yang sudah bersekolah) atau terlambat bersekolah (penduduk usia lebih dari 12 tahun masih bersekolah di SD atau sederajat), persentase penduduk miskin, persentase rumah tangga kumuh, kepadatan penduduk, persentase sanitasi total berbasis masyarakat, persentase akses sanitasi layak, luas lahan kebun sawit, jumlah perusahaan tambang, dan jumlah petani karet yang ada di setiap Provinsi. Sedangkan variabel dependen adalah prevalensi Malaria menggunakan annual parasite incidence (API) dengan satuan jumlah kasus Malaria positif/1000 penduduk.

Analisis data dilakukan dengan melihat distribusi frekuensi determinan kejadian Malaria dan uji korelasi spearman pada tingkat kepercayaan 95\%. Dilakukan pula analisis trend kejadian Malaria (API) selama sepuluh tahun terakhir di Indonesia.

\section{HASIL}

Grafik 1 memperlihatkan, rata-rata kejadian Malaria 10 tahun terakhir cenderung stabil, namun mengalami peningkatan yang sangat signifikan pada tahun 2006, kemudian mengalami penurunan kembali pada tahun 2007, dan mulai kembali stabil pada tahun berikutnya. Angka annual parasite incidence (API) di Indonesia sebesar $0,84 \%$ dengan API tertinggi pada Provinsi Papua $(45,85 \%$ ) dan terendah pada Provinsi Jawa Timur $(0,01 \%$ ), sedangkan Provinsi Banten merupakan Provinsi Bebas Malaria $(0,00 \%)$.

Tabel 1 memperlihatkan, distribusi penduduk berpendidikan terendah di Provinsi Papua $(94,74 \%)$ dan tertinggi di Kalimantan Tengah (114,01\%). Distribusi penduduk miskin tertinggi yaitu di Provinsi Papua (28,40\%), sedangkan terendah di DKI Jakarta $(3,75 \%)$.
Persentase rumah tangga kumuh tertinggi di Provinsi Papua $(44,87 \%)$ dan terendah di Provinsi DI Yogyakarta (1,67\%). Proporsi desa ber-STBM (Sanitasi Total Berbasis Masyarakat) tertinggi di Provinsi DI Yogyakarta (96,35\%), dan Provinsi Papua berada posisi terendah $(7,65 \%)$. Persentase penduduk yang memiliki akses sanitasi layak, terendah di Provinsi Papua $(30,97 \%)$ dan Provinsi DKI Jakarta berada pada posisi tertinggi $(90,42 \%)$. Lahan kebun sawit terluas di Indonesia berada di Provinsi Riau (2.462.095 ha) dan yang terendah di Provinsi Gorontalo (4.300 ha), namun terdapat 8 Provinsi yang tidak memiliki kebun sawit di Daerahnya. Perusahaan tambang yang tersebar di berbagai daerah dengan jumlah terbanyak berada di Provinsi DKI Jakarta (165 perusahaan), sedangkan di Provinsi Nusa Tenggara Timur, Banten, dan Yogyakarta memiliki perusahaan tambang yang sangat sedikit dibandingkan Provinsi DKI Jakarta (1 perusahaan), namun ada 2 provinsi yang tidak memiliki perusahaan tambang di daerahnya. Jumlah petani karet terbanyak pada Provinsi Jawa Barat (27.649 orang) dan Provinsi Bali dengan jumlah paling sedikit (252 orang) namun terdapat 15 provinsi yang tidak memiliki petani karet.

Tabel 2 memperlihatkan, Angka annual parasite incidence di Indonesia adalah 0,84\%. Pendidikan masyarakat yang tergolong rendah sebesar 109,31\%. Dari 258.924.888 jiwa penduduk Indonesia tahun 2016, persentase penduduk miskin sebesar $10,70 \%$ dengan rumah tangga kumuh sebesar 6,08\%. Dari total desa dan kelurahan sebesar 80.314 hanya $42,4 \%$ yang termasuk Desa Sanitasi Total Berbasis 


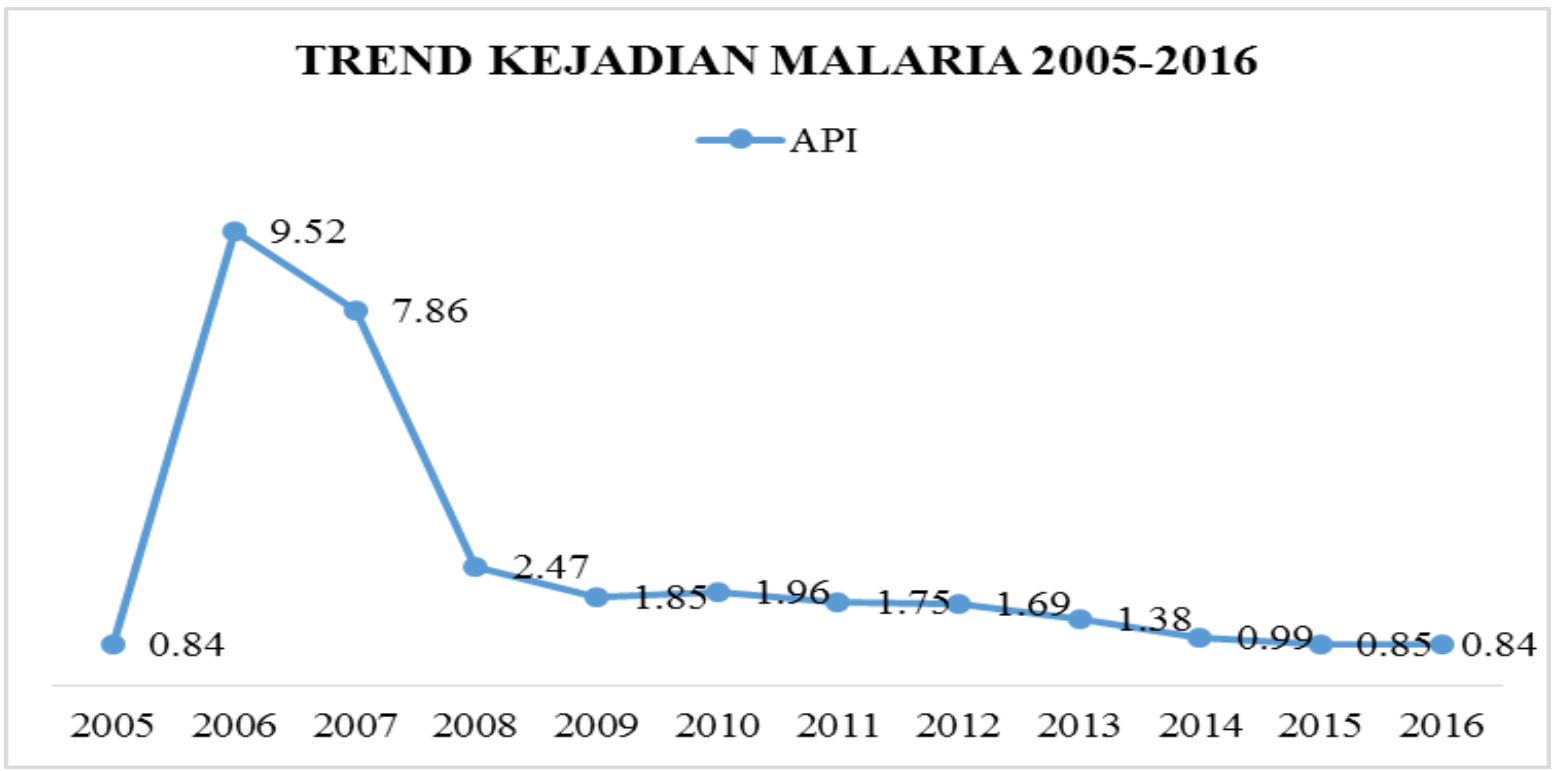

Grafik 1. Trend Rata-rata Kejadian Malaria di Indonesia, 2005-2016

Tabel 2. Distribusi Determinan Kejadian Malaria di Indonesia Tahun 2016

\begin{tabular}{lc}
\hline \multicolumn{1}{c}{ Variabel } & Angka \\
\hline Annual Parasite Incidence (\%) & 0,84 \\
Pendidikan Rendah (\%) & 109,31 \\
Penduduk Miskin (\%) & 10,70 \\
Rumah Tangga Kumuh (\%) & 6,08 \\
Desa ber-STBM (\%) & 42,4 \\
Akses Sanitasi Layak (\%) & 67,20 \\
Luas Lahan Kebun Sawit (Ha) & 11.672 .801 \\
Jumlah Perusahaan Tambang & 850 \\
Jumlah Petani Karet & 246.479 \\
\hline
\end{tabular}

Tabel 3. Hasil Uji Korelasi Beberapa Determinan terhadap Kejadian Malaria

\begin{tabular}{lcc}
\hline \multicolumn{1}{c}{ Variabel } & r & P-value \\
\hline Annual Parasite Incidence (\%) & 1000 & NA \\
Pendidikan Rendah (\%) & $0,417^{*}$ & 0,014 \\
Penduduk Miskin (\%) & $0,470^{* *}$ & 0,005 \\
Rumah Tangga Kumuh (\%) & $0,571^{* *}$ & 0,000 \\
Desa STBM (\%) & $-0,409 * *$ & 0,016 \\
Akses Sanitasi Layak (\%) & $-0,419 *$ & 0,012 \\
Luas Lahan Kebun Sawit (ha) & 0,119 & 0,495 \\
Jumlah Perusahaan Tambang & 0,096 & 0,585 \\
Jumlah Petani Karet & $-0,153$ & 0,379 \\
\hline Ket : & \\
* Korelasi signifikan pada tingkat 0,05 & \\
** Korelasi signifikan pada tingkat 0,01 & \\
\hline
\end{tabular}


Masyarakat (STBM) namun akses sanitasi layak sudah mencapai $67,20 \% .^{9}$ Luas perkebunan sawit sebesar 11.672.801 ha, dengan jumlah perusahaan tambang sebanyak 850 yang tersebar di seluruh Indonesia. Sedangkan jumlah petani karet sebanyak 246.479 orang.

Tabel 3 menunjukkan bahwa determinan yang berkorelasi dengan kejadian Malaria adalah persentase masyarakat berpendidikan rendah $(\mathrm{r}=0,417$; P-value $=0,014)$; persentase penduduk miskin ( $\mathrm{r}=0,470 ; P$-value $=0,005)$; persentase rumah tangga kumuh $(\mathrm{r}=0,571 ; P$ value $=0,000)$; persentase Desa ber-STBM $(r=$ $-0,409 ; \quad P$-value $=0,016) ;$ persentase akses sanitasi layak $(\mathrm{r}=-0,419 ; P$-value $=0,012)$. Semakin banyak proporsi penduduk berpendidikan rendah, penduduk miskin, dan rumah tangga kumuh diikuti dengan meningkatnya angka kejadian Malaria. Selain itu, semakin rendah proporsi Desa ber-STBM dan persentase penduduk yang mempunyai akses sanitasi layak diikuti dengan meningkatnya kejadian Malaria.

Namun beberapa variabel lainnya yaitu luas perkebunan sawit, jumlah perusahaan tambang, dan jumlah petani karet belum terbukti mempunyai korelasi yang signifikan dengan kejadian Malaria di Indonesia. Terlihat bahwa proporsi rumah tangga kumuh di suatu wilayah berkorelasi paling kuat dengan kejadian Malaria di wilayah tersebut.

\section{PEMBAHASAN}

Malaria merupakan penyakit infeksi yang muncul kembali setelah terjadinya penurunan yang signifikan sebelumnya dan sekarang muncul kembali dengan peningkatan yang cepat (re-emerging disease). ${ }^{11}$ Kejadian penyakit menular pada suatu wilayah berhubungan dengan budaya, ekosistem dan kondisi sosial kependudukan, dan juga merupakan outcome dari hubungan interaktif antara kelompok faktor risiko penyakit yaitu, variabel lingkungan dan sosio demografi kependudukan seperti umur, gender, genetika dan perilaku. Selain itu juga dipengaruhi oleh kualitas dan akses pelayanan kesehatan. Kurangnya kesadaran masyarakat dalam membiasakan perilaku hidup bersih dan sehat atau perubahan perilaku yang mendukung aksesibilitas agent dalam menginfeksi host serta pencemaran lingkungan yang cukup intens sebagai konsekuensi akibat eksplorasi, manipulasi, dan eksploitasi terhadap lingkungan biologis, kimiawi, fisik dan sosial. ${ }^{12}$

Kondisi Malaria di Indonesia sebagian besar daerah masih merupakan daerah endemik terhadap infeksi Malaria, Indonesia bagian timur seperti Papua, Maluku, Nusa Tenggara, Sulawesi, Kalimantan dan bahkan beberapa daerah di Sumatera seperti Lampung, Bengkulu dan Riau. Daerah di Jawa dan Bali dengan endemitas sudah sangat rendah, masih sering dijumpai kasus malaria, hal ini disebabkan mudahnya transportasi untuk mobilisasi penduduk, sehingga sering menyebabkan timbulnya malaria import. ${ }^{13}$

Angka annual parasite incidence (API) di Indonesia menunjukkan bahwa Indonesia telah mencapai Low Cumulative Incidence dikarenakan API $<1$. Suatu Wilayah dikatakan endemis rendah apabila angka API $<1$ atau AMI $<25$ per mil, endemis sedang apabila angka API 1-5 atau AMI 25-50 per mil, dan endemis tinggi apabila angka API $>5$ atau AMI $>50$ per mil. ${ }^{14}$

Provinsi Papua mencapai angka annual parasite incidence (API) tertinggi diikuti dengan Papua Barat dan Nusa Tenggara Timur yang menunjukkan High Cumulative Incidence (API $=5-49)$ sedangkan 29 provinsi lainnya menunjukkan Low Cumulative Incidence (API < 1) namun pada Provinsi Banten dan Bali menunjukkan kondisi Bebas Malaria (Kasus Nol). ${ }^{1}$

Hasil studi ini menemukan bahwa ada korelasi positif antara persentase jumlah penduduk berpendidikan rendah dengan kejadian Malaria. Semakin banyak proporsi 
penduduk berpendidikan rendah di suatu wilayah akan diikuti dengan kenaikan angka kejadian Malaria. Hasil ini sama dengan hasil yang ditemukan pada Riskesdas (2007), dimana kejadian Malaria banyak pada kelompok penduduk berpendidikan rendah dibandingkan pada penduduk berpendidikan tinggi. ${ }^{10}$ Tingkat pendidikan tidak berpengaruh langsung terhadap kejadian Malaria, namun mempengaruhi jenis pekerjaan dan perilaku seseorang.

Hasil penelitian lain menyatakan bahwa masyarakat yang tingkat pendidikannya rendah berpeluang terkena Malaria sebesar 1,8 kali dibandingkan dengan yang berpendidikan tinggi dimana sejalan dengan penelitian lainnya bahwa ada hubungan antara pendidikan dengan kejadian Malaria $(P$-value $=<0,05)$. Pendidikan rendah berisiko 4,4 kali mengalami kejadian Malaria dibandingkan pendidikan tinggi. ${ }^{17}$

Tingkat pendidikan yang tinggi akan meningkatkan pengetahuan masyarakat tentang pentingnya kesehatan di sekitar rumahnya. Semakin rendah tingkat pendidikan seseorang maka akan semakin rendah pula pola pikirnya dalam menghadapi lingkungan rumah dan merasa enggan untuk mendapatkan informasi terkait penyakit malaria. ${ }^{16}$

Tingginya proporsi penduduk berpendidikan rendah harus menjadi perhatian, karena akan menyebabkan rendahnya derajat kesehatan secara umum. Hal ini sudah umum terjadi di negara-negara berkembang seperti Thailand dan Philipina. Dengan demikian, upaya peningkatan pendidikan masyarakat harus terus dilakukan oleh Pemerintah, karena seseorang yang memiliki pendidikan yang lebih tinggi akan mencegah dirinya sendiri agar terhindar dari penyakit Malaria atau penyakit lainnya karena mereka lebih mudah memahami informasi yang didapat termasuk informasi terkait Malaria. Hal ini karena informasi yang tersedia lebih banyak ditemukan di media leaflet, poster dan penyuluhan dibandingkan dari petugas kesehatan. ${ }^{12}$
Hasil studi ini menunjukkan bahwa proporsi penduduk miskin juga berkorelasi positif dengan kejadian Malaria. Semakin banyak jumlah persentase penduduk miskin di suatu wilayah, akan diikuti dengan peningkatan angka kejadian Malaria. Hasil studi ini sejalan dengan analisis data Riset Kesehatan Dasar tahun 2013, dimana status ekonomi merupakan faktor risiko yang berhubungan dengan kejadian Malaria, status ekonomi masyarakat kuintil menengah ke bawah lebih berisiko menderita Malaria dibandingkan kuintil kaya. Hal ini juga sejalan dengan penelitian lainnya yang menunjukkan adanya hubungan yang signifikan antara penghasilan per bulan dengan kejadian Malaria di daerah perbatasan. ${ }^{18}$

$$
\text { Kemiskinan berperanan dalam }
$$
penyebaran penyakit infeksi dari berbagai macam penyakit menular, hal ini dikarenakan kemiskinan secara absolut ditentukan berdasarkan ketidakmampuan untuk mencukupi kebutuhan pokok minimum seperti pangan, sandang, kesehatan, perumahan, dan pendidikan yang diperlukan untuk bisa hidup dan bekerja. ${ }^{13}$ Malaria sangat mempengaruhi keadaan penduduk miskin di daerah terpencil yang jauh dari akses pelayanan kesehatan. Penduduk miskin cenderung tidak memperhatikan kebutuhan sandang dan papan, dikarenakan sulitnya dalam memenuhi kebutuhan pangan sehari-hari. Dengan demikian keadaan kondisi rumah hanya terbuat dari bahan yang tidak memadai yang menyebabkan nyamuk dapat masuk dalam rumah dan terjadi infeksi dalam rumah. Selain itu juga menyebabkan tidak terpenuhinya kebutuhan gizi secara seimbang 
Tabel 1. Distribusi Beberapa Determinan Kejadian Malaria di Indonesia Menurut Provinsi, Tahun 2016

\begin{tabular}{|c|c|c|c|c|c|c|c|c|c|c|}
\hline No & Provinsi & $\begin{array}{c}\text { Annual } \\
\text { Parasite } \\
\text { Incidence } \\
(\%)\end{array}$ & $\begin{array}{c}\text { Jumlah } \\
\text { Pendidikan } \\
\text { Rendah }\end{array}$ & $\begin{array}{l}\text { Persentase } \\
\text { Penduduk } \\
\text { Miskin }\end{array}$ & $\begin{array}{c}\text { Persentase } \\
\text { Rumah } \\
\text { Tangga } \\
\text { Kumuh }\end{array}$ & $\begin{array}{l}\text { Persentase } \\
\text { STBM }\end{array}$ & $\begin{array}{c}\text { Persentase } \\
\text { Akses } \\
\text { Sanitasi } \\
\text { Layak }\end{array}$ & $\begin{array}{c}\text { Jumlah Luas } \\
\text { Lahan } \\
\text { Kebun Sawit } \\
\text { (Ha) }\end{array}$ & $\begin{array}{c}\text { Jumlah } \\
\text { Perusahaan } \\
\text { Tambang }\end{array}$ & $\begin{array}{c}\text { Jumlah } \\
\text { Petani } \\
\text { Karet }\end{array}$ \\
\hline 1 & Aceh & 0,05 & 111,26 & 16,43 & 10,25 & 22,62 & 61,02 & 462.010 & 6 & 15.020 \\
\hline 2 & Sumatera Utara & 0,27 & 110,89 & 10,27 & 8,90 & 18,45 & 72,43 & 1.466 .420 & 12 & 763.88 \\
\hline 3 & Sumatera Barat & 0,12 & 110,39 & 7,14 & 8,84 & 45,65 & 52,93 & 413.453 & 33 & . \\
\hline 4 & Riau & 0,03 & 110,04 & 7,67 & 4,70 & 61,36 & 70,67 & 2.462 .095 & 20 & 18.135 \\
\hline 5 & Jambi & 0,14 & 112,97 & 8,37 & 5,36 & 35,10 & 65,11 & 757.214 & 30 & 1.575 \\
\hline 6 & Sumatera Selatan & 0,28 & 114,33 & 13,39 & 9,99 & 42,81 & 64,51 & 1.064 .373 & 81 & 22.417 \\
\hline 7 & Bengkulu & 1,45 & 113,13 & 17,03 & 8,78 & 35,00 & 49,45 & 308.669 & 9 & 9.971 \\
\hline 8 & Lampung & 0,40 & 111,44 & 13,86 & 3,07 & 41,17 & 58,29 & 202.774 & 16 & 7.808 \\
\hline 9 & $\begin{array}{l}\text { Kepulauan Bangka } \\
\text { Belitung }\end{array}$ & 0,11 & 111,75 & 5,04 & 2,72 & 80,62 & 82,49 & 222.226 & 60 & . \\
\hline 10 & Kepulauan Riau & 0,36 & 108,86 & 5,84 & 2,02 & 36,23 & 78,71 & 20.759 & 14 & 2.019 \\
\hline 11 & DKI Jakarta & 0,01 & 104,32 & 3,75 & 5,74 & 9,74 & 90,42 & . & 165 & . \\
\hline 12 & Jawa Barat & 0,01 & 108,09 & 8,77 & 6,36 & 40,45 & 63,12 & 14.331 & 13 & 27.649 \\
\hline 13 & Jawa Tengah & 0,03 & 109,46 & 13,19 & 1,86 & 60,88 & 70,19 & & 4 & 12.709 \\
\hline 14 & DI Yogyakarta & 0,03 & 106,75 & 13,10 & 1,67 & 96,35 & 85,60 & . & 1 & . \\
\hline 15 & Jawa Timur & 0,01 & 108,17 & 11,85 & 2,76 & 68,21 & 67,47 & . & 21 & 10.294 \\
\hline 16 & Banten & . & 109,05 & 5,36 & 4,44 & 84,22 & 72,92 & 19.043 & 1 & 2.817 \\
\hline 17 & Bali & . & 104,97 & 4,15 & 1,90 & 55,59 & 88,74 & . & . & 252 \\
\hline 18 & Nusa Tenggara Barat & 0,24 & 110,78 & 16,02 & 7,83 & 95,07 & 69,76 & . & 1 & . \\
\hline 19 & Nusa Tenggara Timur & 5,41 & 114,12 & 22,01 & 29,37 & 68,28 & 38,74 & . & 4 & . \\
\hline 20 & Kalimantan Barat & 0,06 & 113,75 & 8,00 & 7,55 & 27,13 & 51,46 & 1.017 .596 & 11 & 7.830 \\
\hline 21 & Kalimantan Tengah & 0,19 & 114,01 & 5,36 & 7,12 & 47,16 & 50,30 & 1.215 .078 & 39 & 4.316 \\
\hline 22 & Kalimantan Selatan & 0,52 & 111,63 & 4,52 & 5,54 & 52,04 & 60,71 & 569.654 & 71 & 12.213 \\
\hline 23 & Kalimantan Timur & 0,35 & 110,04 & 6,00 & 4,21 & 20,29 & 75,60 & 787.512 & 87 & 10.503 \\
\hline 24 & Kalimantan Utara & 0,03 & 103,96 & 6,99 & 7,74 & 13,36 & 64,26 & 166.474 & 11 & . \\
\hline 25 & Sulawesi Utara & 0,72 & 110,26 & 8,20 & 8,34 & 7,88 & 74,75 & & 2 & . \\
\hline 26 & Sulawesi Tengah & 0,49 & 105,78 & 14,09 & 10,42 & 34,81 & 59,76 & 157.400 & 58 & 658 \\
\hline 27 & Sulawesi Selatan & 0,12 & 109,71 & 9,24 & 4,57 & 81,94 & 76,05 & 55.310 & 7 & 2.829 \\
\hline 28 & Sulawesi Tenggara & 0,44 & 109,96 & 12,77 & 7,34 & 29,24 & 67,44 & 48.961 & 39 & . \\
\hline 29 & Gorontalo & 0,15 & 108,34 & 17,63 & 11,69 & 45,07 & 59,38 & 4.300 & . & . \\
\hline 30 & Sulawesi Barat & 0,09 & 106,23 & 11,19 & 12,21 & 65,02 & 59,35 & 116.356 & 5 & . \\
\hline 31 & Maluku & 3,95 & 110,30 & 19,26 & 12,62 & 13,38 & 66,31 & 11.213 & 9 & 1076 \\
\hline 32 & Maluku Utara & 2,44 & 113,70 & 6,41 & 9,45 & 19,68 & 64,13 & . & 10 & . \\
\hline 33 & Papua Barat & 6,79 & 111,49 & 24,88 & 12,03 & 20,80 & 63,69 & 54.042 & 7 & . \\
\hline 34 & Papua & 45,85 & 94,74 & 28,40 & 44,87 & 7,65 & 30,97 & 55.592 & 3 & . \\
\hline Total & Indonesia & $\mathbf{0 , 8 4}$ & 109,31 & 10,70 & $\mathbf{6 , 0 7}$ & 42,24 & 67,20 & 11.672 .801 & 850 & 246.479 \\
\hline
\end{tabular}


sehingga daya tahan tubuh terhadap penyakit Malaria terbilang rendah mengakibatkan mudahnya terserang penyakit Malaria. Hal ini sejalan dengan penelitian lain yang dilakukan di Provinsi Sumatera Selatan yang menyatakan bahwa ada hubungan yang signifikan antara sosial ekonomi dengan kejadian Malaria. ${ }^{19}$ Penduduk miskin biasanya berpenghasilan rendah. Hasil penelitian menunjukkan bahwa ada hubungan antara penghasilan dengan kejadian Malaria. Penghasilan merupakan faktor yang terkait dengan program penanggulangan penyakit Malaria, artinya penduduk yang mempunyai penghasilan yang memadai memungkinkan berpartisipasi aktif dalam program penanggulangan Malaria. Penghasilan merupakan faktor yang terkait dengan program penanggulangan penyakit Malaria. Penduduk yang mempunyai penghasilan memadai (sesuai Upah Minimum Provinsi) cenderung untuk berpartisipasi aktif dalam program penanggulangan Malaria. ${ }^{17}$

Hasil studi ini juga menemukan bahwa lingkungan kumuh berkorelasi dengan kejadian Malaria. Faktor ini mempunyai korelasi yang sangat kuat dengan kejadian Malaria di Indoensia. Dimana proporsi wilayah Provinsi dengan jumlah lebih banyak daerah kumuhnya akan diikuti dengan meningkatnya angka kejadian Malaria di wilayah tersebut. Hal ini memperkuat teori yang menyatakan bahwa Malaria merupakan salah satu penyakit berbasis lingkungan.

Kita ketahui bahwa lingkungan rumah yang sehat harus memiliki sarana drainase yang baik agar tidak menjadi tempat perindukan vektor penyakit. Rumah tinggal yang sehat harus memenuhi syarat bahan bangunan, terbuat dari bahan yang tidak menjadi tempat berkembangnya mikroorganisme. Lingkungan rumah yang ideal bukanlah sekedar bangunan tempat berlindung namun harus menjadi tempat yang bebas dari gangguan hama, polusi, dan penyakit. Lingkungan tempat tinggal yang kumuh serta sanitasi buruk menjadi penyebab utama terjangkitnya penyakit Malaria yang merupakan tempat bersarangnya nyamuk Anopheles. Hal ini sejalan dengan penelitian berdasarkan analisis data riskesdas 2010 yang menunjukkan bahwa responden yang rumahnya kumuh berisiko lebih besar untuk menderita Malaria. ${ }^{20}$

Sanitasi Total Berbasis Masyarakat (STBM) adalah suatu strategi/program intervensi yang menitikberatkan pada pencapaian kondisi sanitasi total di masyarakat melalui perubahan perilaku higienis, dengan melibatkan (memberdayakan) seluruh komponen di dalam masyarakat. Suatu masyarakat dikatakan mencapai kondisi sanitasi total apabila seluruh komponen di dalam masyarakat itu melaksanakan atau melakukan lima (5) pilar STBM yaitu : 1. Tidak buang air besar sembarangan (BABS); 2. Cuci tangan pakai sabun (CTPS); 3. Mengelola air minum dan makanan yang aman; 4. Mengelola sampah dengan aman; 5. Mengelola limbah cair rumah tangga dengan aman. ${ }^{21}$

Hasil studi ini juga menemukan bahwa persentase jumlah Desa ber-sanitasi total berbasis masyarakat (STBM) yang ada di suatu wilayah Provinsi memiliki korelasi negatif dengan kejadian Malaria di wilayah tersebut. Hal ini berarti semakin tinggi proporsi desa berSTBM maka akan diikuti dengan menurunnya angka kejadian Malaria di suatu wilayah, demikian pula sebaliknya semakin rendah proporsi desa ber-STBM di suatu wilayah akan diikuti dengan meningkatnya angka kejadian Malaria. Rendahnya desa ber-STBM di beberapa wilayah di Indonesia, dikarenakan masih rendahnya proporsi desa dan kelurahan yang memiliki pengelola sanitasi total berbasis masyarakat. Rendahnya peningkatan akses sanitasi disebabkan dua hal, yaitu proporsi wilayah yang belum memiliki organisasi pengelola STBM dan kinerja organisasi pengelola STBM belum optimal. Lima belas 
dari tujuh belas organisasi pengelola STBM di suatu wilayah mengalami kendala dalam pengorganisasiannya. ${ }^{22}$

Hasil studi ini sejalan dengan penelitian yang dilakukan di Kabupaten Wonogiri dimana jumlah tim atau organisasi Sanitasi Total Berbasis Masyarakat (STBM) desa/kelurahan yang terbentuk di setiap Kecamatan masih belum sesuai jumlah desa/kelurahan. Penyebab rendahnya peningkatan akses sanitasi di tingkat desa/kelurahan disebabkan beberapa hal, yaitu: 1) kebijakan Peraturan Bupati nomor 12 Tahun 2015 tentang STBM belum tersebar dengan baik, 2) kelengkapan administrasi dan perangkat organisasi belum menjadi prioritas pemenuhan, 3) hasil kegiatan pemicuan yang tidak segera ditindaklanjuti dengan pemberian opsi solusi. ${ }^{7}$

Malaria merupakan salah satu penyakit yang kejangkitannya dapat dicegah dengan meningkatkan kualitas perumahan dan kondisi penghidupan, nutrisi yang lebih baik dan perawatan kesehatan primer yang menyeluruh. ${ }^{20}$ Lingkungan berperan besar dalam penyebaran penyakit baik melalui air, udara, tanah, biota, maupun manusia beserta perilakunya. Sejalan dengan hal tersebut Malaria sebagai salah satu penyakit yang bersumber dari faktor lingkungan, penularannya di suatu daerah sangat berkaitan dengan kondisi lingkungan setempat. Lingkungan permukiman merupakan salah satu aspek penting yang perlu diperhatikan dalam upaya pencegahan dan penanggulangan penularan penyakit Malaria di Indonesia. ${ }^{1}$

Hasil studi ini menunjukkan bahwa akses sanitasi layak memiliki korelasi negatif dengan angka kejadian Malaria di sutau wilayah. Rendahnya proporsi akses penduduk terhadap sanitasi yang layak di suatu wilayah akan diikuti dengan meningkatnya angka kejadian Malaria di wilayah tersebut. Hasil studi ini sejalan dengan penelitian lanjutan berdasarkan data Riskesdas 2013 yang menemukan bahwa factor yang berhubungan dengan kejadian Malaria adalah jarak memperoleh air kebutuhan minum dengan jarak 101-1000 meter. Selain jarak, waktu memperoleh air kebutuhan minum juga merupakan faktor risiko terhadap kejadian Malaria dengan waktu 31-60 menit. ${ }^{16}$

Studi ini memiliki keterbatasan dikarenakan menggunakan rancangan studi ekologi (studi korelasi). Studi ekologi adalah salah satu bentuk penelitian deskriptif. Penelitian deskriptif merupakan studi awal sebagai dasar untuk memformulasikan hipotesis. Studi terhadap aggregate tidak dapat ditarik simpulan bahwa korelasi yang terjadi pada suatu kelompok juga akan terjadi di tingkat individu. Hal ini disebut dengan ecological fallacy. Perlu dilakukan penelitian lanjut untuk membuktikan adanya korelasi pada tingkat individu. Disamping itu, hanya data yang tersedia dan lengkap pada analisis ini menggunakan profil kesehatan tahun 2016 sehingga tidak dapat melakukan analisis data pada tahun terbaru. Perlu dilakukan kembali analisis menggunakan data ter-update dan dengan jumlah variabel yang lebih bervariasi seperti program atau kebijakan yang ada di suatu wilayah.

\section{KESIMPULAN DAN SARAN}

Ada korelasi positif antara proporsi penduduk berpendidikan rendah, jumlah penduduk miskin, dan persentase rumah tangga kumuh. Sedangkan persentase Desa ber-sanitasi total berbasis masyarakat (STBM), dan akses sanitasi layak menunjukkan korelasi negatif dengan kejadian Malaria. Tidak ada korelasi antara luas lahan kebun sawit, jumlah perusahaan tambang, dan jumlah petani karet dengan kejadian Malaria.

Pemerintah diharapkan melakukan upaya-upaya peningkatan ekonomi kerakyatan serta memberikan edukasi kepada masyarakat secara intensif dan berkesinambungan agar tingkat sosial ekonomi masyarakat meningkat serta sanitasi dan kesehatan lingkungan menjadi 
lebih baik. Petugas kesehatan diharapkan lebih aktif dalam melakukan promosi kesehatan terkait determinan kejadian Malaria yang ditemukan seperti akses sanitasi layak, lingkungan kumuh dan jumlah desa ber-STBM, dengan lebih menekankan pada peningkatan pengetahuan secara informal terhadap pencegahan dan penanggulangan Malaria dikarenakan Pendidikan rendah berkorelasi dengan angka kejadian Malaria. Masyarakat diharapkan lebih memperhatikan lingkungan sekitar yang dapat menjadi potensi penularan penyakit Malaria agar menekan angka kejadian Malaria di wilayahnya.

\section{REFERENSI}

1. Kementrian Kesehatan Republik Indonesia. Pusat Data dan Informasi Malaria. 2016

2. Communicable Desease Control. Impact of malaria. 2010. Available at: http://www. cdc. gov/malaria/malaria_worldwide/impact. html.

3. Communicable Desease Control. CDC and Malaria. 2014. Available at : www.cdc.gov/malaria.

4. Kementrian Kesehatan Republik Indonesia. Profil Kesehatan Indonesia 2015. 2016 : Jakarta

5. Dinas Kesehatan Provinsi Nusa Tenggara Timur Departemen Kesehatan Republik Indonesia. Laporan Kasus malaria di Provinsi Nusa Tenggara Timur. Kupang : Dinas Kesehatan Provinsi Nusa Tenggara Timur Departemen Kesehatan Republik Indonesia; 2009.

6. Utara BM, Mayulu N. Hubungan Sanitasi Lingkungan Dengan Kejadian Malaria Pada Murid Sekolah Dasar Di Kabupaten Bolang Mongondow Utara. Ejournal Keperawatan . 2013; 1 (1) : 1-7
7. Ichwanudin. Kajian Dampak Sanitasi Total Berbasis Masyarakat Terhadap Akses Sanitasi di Kabupaten Wonogiri. Jurnal Kesehatan Lingkungan Indonesia. 2016; 15 (2) : 46-49.

8. Rustam. Faktor-faktor Lingkungan, Perilaku yang Berhubungan dengan Kejadian Malaria pada Penderita yang Mendapat Pelayanan di Puskesmas Kabupaten Sarolangun Provinsi Jambi. Universitas Indonesia. Depok. 2002 (baru)

9. Frits, Wamaer, Hubungan Kondisi Fisik Bangunan Rumah dan Tempat Perindukan Nyamuk dengan Kejadian Malaria Pada Anak Umur 6-59 Bulan di Unit Pelayanan Kesehatan di Fakfak, Thesis Program Pasca Sarjana FKM-UI Depok 2003.

10. Widyaningrum, D. Studi Ekologi Hubungan Prevalensi Malaria, Konsumsi Makanan, dan Kemiskinan Dengan Prevalensi Anemia Pada Penduduk Di Wilayah Perkotaan Indonesia. Fakultas Kesehatan Masyarakat Universitas Indonesia Depok 2012.

11. drh. Fitri Suji D.H. 2017. Apa itu Emerging dan Re-Emerging Disease. VetIndonesia. Available at :https://vetindonesia.com/2017/04/27/ap a-itu-emerging-dan-re-emerging-disease/

12. Hasyim, H. 2008. Manajemen Penyakit Lingkungan Berbasis Wilayah. Jurnal Manajemen Pelayanan Kesehatan, 11(2), pp. 72-76.

13. Kementrian Kesehatan Republik Indonesia. 2011. Epidemiologi Malaria Di Indonesia. Buletin Jendela Data dan Informasi Kesehatan.

14. Wijaya, AM. 2010. Pengukuran Masalah Malaria. Available at : https://www.infodokterku.com/index.ph p/en/82-daftar-isi-content/data/data/85pengukuran-masalah-malaria 
15. Kementrian Kesehatan Republik Indonesia. Profil Kesehatan Indonesia 2016. 2017 : Jakarta

16. Mayasari, R. Andriayani, D. dan Sitorus H. Faktor Risiko yang Berhubungan dengan Kejadian Malaria di Indonesia. Buletin Penelitian Kesehatan. 2015; 44 (1) : 13-24.

17. Sir O, Arsine A, Syam I, Despitasari M. Faktor-Faktor Yang Berhubungan Dengan Kejadian Malaria Di Kecamatan Kebola , Kabupaten Alor ,Provinsi Nusa Tenggara Timur ( NTT ) Tahun 2014. Jurnal Ekologi Kesehatan. 2015; 14 (4) : 334-341

18. Notobroto, HB. Hidajah A. Faktor Risiko Penularan Malaria Di Daerah Berbatasan. J.Penelit. Med. Eksakta. 2009; 8 (2) : 143-151.

19. Moru P, Alor K, Daya B, Ntt KA. Pengaruh Faktor Demografi Dan Riwayat Malaria Terhadap Kejadian Malaria. Jurnal Berkala Epidemiologi. 2016; 4 (3) : 338-48.

20. Wahyuni, E. U. J. I. (2012) Dengan Kejadian Malaria Pada Balita Di Indonesia ( Analisis Data Riskesdas
2010 ) Di Indonesia ( Analisis Data Riskesdas 2010 ).

21. Wijaya, AM. 2015. Mari Mengenal Program Sanitasi Total Berbasis Masyarakat (STBM). Avaliable at : https://www.infodokterku.com/index.ph p/en/97-daftar-isi-content/infokesehatan/sanitasi/205-mari-mengenalprogram-sanitasi-total-berbasismasyarakat-stbm

22. Kementrian Kesehatan Republik Indonesia. Road Map Percepatan Program STBM. 2013. 2013 : Jakarta

23. Wayan N, Adnyanal D. Kejadian Malaria Terkait Lingkungan Pemukiman Di Kabupaten Sumba Barat Provinsi Nusa Tenggara Timur. Jurnal Ekologi Kesehatan. 2015; 14 (2) : 89-95

24. Badan Pusat Statistik. Direktori Perusahaan Pertambangan Besar. 2016 : 1-101.

25. Kementrian Pertanian. Pertanian. Statistik Perkebunan Indonesia. 2016 : 161. Available at: http://ditjebun.pertanian.go.od 